\title{
INVENTÁRIO DAS ÁRVORES PRESENTES NA ARBORIZAÇÃO DE CALÇADAS DA PORÇÃO CENTRAL DO BAIRRO SANTA FELICIDADE-CURITIBA/PR
}

\author{
José Adenilson de Carvalho' ${ }^{1}$, João Carlos Nucci ${ }^{2}$, Simone Valaski ${ }^{3}$ \\ (recebido em 01.07.2009 e aceito para publicação em 24.03.2010)
}

\begin{abstract}
RESUMO
A presença de vegetação nas cidades é de suma importância, especialmente a de porte arbóreo. Uma possibilidade que a arborização urbana nos oferece é a sua utilização como recurso alimentar complementar por parte da população, fato que tem chamado a atenção de vários pesquisadores nos últimos anos. Os objetivos deste trabalho foram o de realizar a contagem e a respectiva identificação das árvores presentes nas calçadas de Santa Felicidade, verificando o percentual e as principais espécies de árvores que produzem alimentos que podem ser consumidos na alimentação humana. Para a realização do inventário, foi escolhida a porção central do bairro, que equivale a aproximadamente $35 \%$ da área total do bairro. Foram encontradas 1806 árvores, sendo que 433 não foram identificadas até o presente momento. Das 1373 árvores identificadas, 279 são consideradas frutíferas alimentares $(20,3 \%$ do total identificado). Entre estas, as três espécies mais presentes somam $57,3 \%$ do total encontrado: o jerivá (Syagrus romanzoffiana), o pinheiro (Araucaria angustifolia) e a pitangueira (Eugenia uniflora). Foi gerado um mapa com a localização das espécies frutíferas. Neste mapa é possível verificar que as árvores frutíferas estão espalhadas principalmente em áreas mais periféricas, em regiões predominantemente residenciais, onde o plantio de árvores é realizado principalmente pelos próprios moradores.
\end{abstract}

Palavras-chave: Vias públicas, alimentação humana, frutíferas, Curitiba (PR).

\footnotetext{
1. Geógrafo, Universidade Federal do Paraná - UFPR. Curitiba, PR. joseac@ufpr.br

2. Biólogo, Profo ${ }^{D}{ }^{\circ}$ do Departamento de Geografia - Universidade Federal do Paraná - UFPR.

Curitiba, PR. nucci@ufpr.br

${ }^{3}$. Geógrafa, Mestre em Geografia Física, Universidade Federal do Paraná - UFPR. Curitiba, PR. svgeog@yahoo.com.br
} 


\title{
INVENTORY OF THE TREES PRESENTS IN THE ARBORIZATION OF THE SIDEWALKS IN THE CENTRAL SECTION OF THE SANTA FELICIDADE DISTRICT - CURITIBA/PR
}

\begin{abstract}
The vegetation presence in the cities is extremely important, especially those in the arborescent size. A possibility which the arborization offers is its utilization as complementary food source for the population, what has called the attention of many researches in the last years. The investigation purpose was to determine the quantification and respective identification of the arborization of the sidewalks in the Santa Felicidade district, checking the percentage and the main tree species which produce food and which can be consumed by human alimentation. To carry out the inventory it was chosen the central area of the district which is nearly equivalent to $35 \%$ of the total district area. It were found 1806 trees, being 433 not identified until now. From the 1373 identified trees, 279 are food considered fruitbearing, which can be used for food purposes $(20.3 \%$ of the total identified). Among these species, the three species with the highest presence sum $57.3 \%$ of the total: the Jeriva (Syagrus romanzoffiana), the Parana Pine (Araucaria angustifolia) and the Pitanga tree (Eugenia uniflora). In the map with the localization of the fruit-bearing species it is possible realize that the fruit-bearing are spread mainly in the peripheral areas, in regions predominantly residential where the tree planting is carried out mainly by the residents themselves.
\end{abstract}

Key-words: Public ways, human food, fruit-bearing, Curitiba (PR).

\section{INTRODUÇÃO}

A vegetação, principalmente a arbórea, é de suma importância para as áreas urbanizadas por produzir uma série de benefícios para o ser humano e a fauna. Entre elas podemos citar: estabilizador climático, redutor da poluição atmosférica, barreira acústica, equilíbrio psicossocial do homem ao aproximá-lo de um ambiente mais natural, melhoria da qualidade ambiental e paisagística, sombra e proteção contra os ventos, a melhoria do ciclo hidrológico, redução das despesas com condicionamento térmico, promoção da diversidade de espécies, qualificação ambiental e paisagística dos imóveis valorizando-os economicamente, a importância das árvores para a produção de madeira em bosques urbanos e alimentos nos quintais,,proporcionar espaço vital para os animais no interior das cidades, principalmente para a avifauna, que se utilizam das árvores como abrigo e 
fornecedoras de alimentos,, o controle de enchentes e inundações e ainda para o seqüestro de carbono, contribuindo para a diminuição do aquecimento global, os benefícios psicológicos como o combate ao stress e os ganhos políticos e econômicos.

Algumas cidades no Brasil já adotam a cobertura vegetal arbórea como apelo ecológico, tais como Curitiba, conhecida como capital ecológica, Maringá, a cidade mais arborizada do Brasil e João Pessoa, a cidade verde do Brasil. Esse artifício contribui para a especulação imobiliária, aumentando o preço das propriedades localizadas próximas a parques e ruas muito arborizadas, bem como para a intensificação do turismo.

Outras funções dessa vegetação urbana é a estabilização das superfícies por meio da fixação dos solos pelas raízes das plantas, proteção da qualidade da água, pois impede que poluentes escorram para os rios, o equilíbrio do índice de umidade no ar, a proteção das nascentes e dos mananciais, a organização e composição de espaços no desenvolvimento de atividades humanas, a segurança das calçadas como acompanhamento viário, o contraste de texturas, consumo de vegetais e frutas frescas, entre outras.

Também, nesse sentido, pode-se citar Schumacher (1973) que explica que Buda incluiu em seus ensinamentos a obrigação de se plantar e cuidar da consolidação de uma árvore de cinco em cinco anos, no mínimo e que enquanto isso foi observado, toda Índia estava coberta de árvores, livre de poeira, com água em abundância, muita sombra, alimento e materiais.

\section{Arborização com Árvores Frutíferas}

\subsection{Discussão das Idéias Contra e a Favor}

Quando se pensa em uma arborização viária com árvores frutíferas, tem-se uma questão bastante polêmica, pois grande parte dos estudiosos é contra a idéia, mas podemse encontrar outros que se posicionam a favor.

Santos e Mór (1999) se posicionam contra esse tipo de arborização, principalmente quando é realizada pelos próprios moradores, pela falta de manutenção e manejo adequados.

Santos e Teixeira (2001) indicam que a frutificação das espécies poderá representar um efeito ornamental e servir de atrativo para a fauna local, mas desaconselham as espécies que produzam frutos grandes como a mangueira, pois esses frutos podem cair sobre a calçada ou sobre pedestres que circulam no local. Para resolver esse problema, citam que existem referências bibliográficas internacionais que apontam soluções para a utilização dessas espécies, tais como, o uso de reguladores de crescimento que atuam na diminuição ou redução da frutificação. 
Soares (1998) desaconselha a utilização de árvores que possuam frutos comestíveis, principalmente quando as mesmas sujam a pavimentação. Para o autor essas árvores podem ser utilizadas na área rural para alimentação do gado.

Milano (1996) defende a idéia de que usar árvores frutíferas na arborização urbana não é aconselhável, pois além de não resolver e nem amenizar a fome dos menos favorecidos, causam sujeira nas vias públicas e servem de alimento para vetores de doenças, tais como moscas, ratos e baratas. Milano e Dalcin (2000) comentam que esse tema nem sequer é tratado na literatura estrangeira mais especializada.

A esse respeito Manica (1997, p.17) relaciona a inexistência de trabalhos nessa linha à falta de profissionais dedicados "[...] à tarefa de planejar e implantar uma arborização urbana racional e equilibrada, especialmente com árvores que florescem e frutificam, formando belos frutos". O autor coloca ainda que a arborização urbana com árvores frutíferas já é realizada em vários locais no Brasil e no mundo, quase sempre de forma espontânea e sem planejamento.

Um bom exemplo disso é o caso da "Rua do Pomar" em São Paulo, que é repleta de laranjeiras, jaboticabeiras, abacateiros, cafeeiros, jamboeiros e macieiras. Nessa rua até os carteiros e entregadores de gás param para apanhar uma fruta, além dos diversos passarinhos que são vistos freqüentemente no local.

Manica (1997) concorda com Santos e Teixeira (2001), em relação ao plantio de árvores que produzam frutos grandes, tais como a mangueira e o abacateiro, que devem ser evitados em ruas onde ocorra trânsito freqüente de pessoas e veículos. Para o autor, a escolha da espécie deve estar de acordo com o local em que será plantada e no caso da mangueira e o abacateiro, entre outras, os frutos são muito pesados e as árvores ficam muito grandes e altas, podendo ocasionar acidentes em pessoas, animais ou veículos durante sua queda. Estas árvores muito altas ainda podem interferir na rede elétrica, causando mais problemas. No entanto elas podem ser plantadas em outros locais, tais como, praças, parques e zoológicos.

Outra autora que defende esta idéia é Sanchotene (1985, p. 111).

[...] há autores que não as recomendam em logradouros públicos, pois não resistiriam à depredação da população, além dos frutos virem a causar problemas à saúde se consumidos ainda imaturos. Mas afinal, já é hora de lutar-se por uma arborização mais racional, sem ter eternamente presente a carência de educação ambiental do povo brasileiro. Há chances de obterem-se bons resultados, até porque já se teve oportunidade de se presenciar algumas iniciativas de particulares nesse sentido. 
Mascaró (2002, p.200) cita o exemplo de Belém do Pará e afirma que "Em ruas centrais foram plantadas mangueiras que, além de proporcionarem uma excelente sombra, fornecem frutos muito apreciados pela população local." Porém, Mascaró e Mascaró (2003) ressalvam que em ruas centrais essas árvores podem causar problemas ao deixar seus frutos caírem sobre os pedestres e motoristas.

Para Manica (1997), outra limitação que existe é o plantio em áreas públicas com muita poluição, como as áreas próximas a certas fábricas, ruas e avenidas com grande circulação de veículos. A poluição poderá causar problemas a saúde das pessoas se as mesmas comerem os frutos sem tirar a casca. Seria melhor começar pelos parques, praças, jardins e amplas avenidas.

Rebatendo a afirmação de Milano (1996), quando diz que esse tipo de arborização não ameniza a miséria na cidade e não ameniza a fome dos menos favorecidos, Bezerra e Fernandes (2000) apresentam dados que justificam esse tipo de iniciativa:

A pobreza extrema, ou indigência, deve atingir hoje cerca de 26 milhões de brasileiros, sem renda suficiente para satisfazer sequer suas necessidades básicas de alimentação. No entanto, chega a aproximadamente 0 dobro desse valor o contingente atual de pessoas que podem ser consideradas pobres.

Mascaró (2002) e Mascaró e Mascaró (2003), em suas obras enfatizam a importância da arborização urbana ao fornecer alimentos à população, principalmente à de baixa renda.

Mesmo com essas restrições, há vários exemplos de situações onde a população convive com esse tipo de árvores. Mais adiante serão apresentados outros exemplos.

\subsection{Exemplos no Mundo}

Nucci (2001) afirma que em outros países os espaços livres também são utilizados para o fornecimento de alimentos.

Manica (1997) apresenta alguns exemplos da Europa, onde em muitas ruas, avenidas e praças de Valência, na Espanha, desfruta-se da presença de muitas espécies de árvores frutíferas tais como, caquizeiro, cerejeira, figueira, figueira-da-índia, laranjeira-doce, laranja-azeda, limoeiro, oliveira, romãzeira, tamareira e tangerineira. Na Ilha de lbiza na Espanha, as exuberantes tamareiras e figueiras estão presentes em muitos locais entre largas avenidas e praças.

Mascaró e Mascaró (2003) acrescentam o exemplo de Sevilha e Córdoba, ainda na Espanha e Tucuman na Argentina, arborizadas com laranjeiras de frutos azedos que, na 
época da frutificação, fornecem grandes quantidades de laranjas que são consumidas pela população para fazer doces.

Mello Filho (1985) apresenta exemplos bem sucedidos de arborização com macieiras e pereiras na Suíça e laranjeiras em Assunción e relaciona o sucesso do empreendimento ao grau de cultura da população.

Ferreira (1985) indica algumas espécies que podem ser aproveitadas na arborização das ruas como a romãzeira anã, goiabeira e nespereira. Sugere ainda que no caso de árvores que produzam frutos se evite seu plantio junto às áreas de circulação. Seria melhor que fossem plantados em áreas protegidas por gramados.

\subsection{Exemplos no Brasil}

No Brasil também temos muitos exemplos. Manica (1997, p.20) apresenta o seguinte em relação à arborização de algumas cidades brasileiras:

Nas cidades de Macapá (AP) e de Belém-do-Pará (PA) muitas ruas e avenidas foram arborizadas com mangueiras e com mudas do jambo-amarelo, formando um lindo colorido na paisagem urbana pelo formato harmonioso das plantas pequenas e adultas, pelo verde intenso de suas folhas, pelas flores coloridas e principalmente pela formação de lindos frutos dourados e pendentes em seus ramos. São conhecidos os coqueiros nas praias da cidade de Salvador, em grandes extensões do litoral da Bahia, na cidade de Vitória e Litoral Norte do Espírito Santo, compondo uma belíssima paisagem litorânea, fornecendo sombra e a presença de locais agradáveis para desfrutar de momentos de lazer, de primeira qualidade e também com as plantas produzindo frutos em quantidade para o consumo dos seus freqüentadores e moradores.

Penteado, (1968) também cita a cidade de Belém, que é chamada de cidade verde ou cidade das mangueiras graças ao projeto de arborização posto em prática a partir do início do século passado.

Manica (1997, p.23) cita o caso de Porto Alegre:

Em grande número de ruas de Porto Alegre, como resultado do plantio desordenado e do crescimento espontâneo, encontram-se presentes árvores de cerejeiras-do-Rio-Grande, figueiras, goiabeiras, laranjeiras, mangueiras, nespereiras, pereiras e pitangueiras. Durante o início da primavera de 1996, no mês de setembro/outubro, em muitas praças e ruas da cidade de Porto Alegre, inúmeras pessoas estavam colhendo e comendo amoras, cerejas-do-RioGrande, nêsperas e pitangas das árvores frutíferas que estavam localizadas nas ruas, avenidas e praças da capital, a grande maioria, como resultado do aparecimento espontâneo ou do trabalho isolado de algum morador. 
Outro exemplo da utilização dessas árvores em Porto Alegre é apresentado por Mascaró e Mascaró (2003, p.79):

Em Porto Alegre, um bairro que antigamente era de veraneio e hoje é de classe média alta - parte do bairro Tristeza - teve algumas de suas ruas arborizadas com nogueiras, árvore resistente às pragas que precisa de poucos cuidados e fornece nozes ricas em nutrientes, aproveitadas pelos funcionários do clube do bairro, jardineiros e empregadas domésticas.

Manica (1997, p. 19) ainda lembra de sua infância na cidade de Garibaldi:

Durante a infância e na fase de adolescência na cidade de Garibaldi, no Rio Grande do Sul, acompanhamos o plantio, crescimento e frutificação da castanheira-portuguesa, na Avenida Rio Branco, uma das principais vias daquela cidade; a castanheira-portuguesa sendo uma planta rústica e de rápido crescimento, formou em pouco tempo uma bela cortina verde e durante a primavera exibia as suas inúmeras flores e com mais alguns meses apareciam as plantas carregadas de frutos que formava um lindo visual e uma paisagem agradável fornecendo sombra especialmente nos meses de verão.

\section{Iniciativas e contribuições para o sucesso da arborização pública voltada à alimentação humana}

Pinho et al (1999) e Tomasini e Sattler (2001) apresentam concordância de idéias quando mostram a preocupação com a desnutrição da população e apontam uma alternativa para diminuir este grave problema, por meio do cultivo de árvores e arbustos que produzam alimentos em seus próprios quintais, ruas e praças. Essa iniciativa também permitiria um aspecto melhor ao ambiente, além de propiciar mais formas de lazer. Reduzindo a fome as pessoas teriam menos doenças, mais longevidade e produtividade.

Toledo e Parente (1985) também recomendam programas de educação ambiental para desenvolver nas crianças o amor e respeito à natureza e concorda com Biondi e Althaus (2005) que afirmam que o vandalismo em áreas urbanas é um problema puramente social e pode ser remediado por meio da educação. As autoras afirmam que em relação à utilização de espécies frutíferas comestíveis, isso depende do aspecto cultural e a conscientização da população.

Ferreira (1985) menciona que grande parte dos problemas enfrentados na arborização urbana está ligada ao desconhecimento das espécies estabelecidas, evidenciando que a adequada seleção contribui para o sucesso do empreendimento. Ou seja, para cada finalidade, existem árvores com características diferentes que devem ser (4) 
estudadas antes de serem utilizadas, tais como, tipo de ramos, tamanho dos frutos, tipos de folhas, raízes, etc.

A própria população demonstra interesse em cultivar esse tipo de árvore como demonstram vários exemplos, principalmente através do que os órgãos públicos chamam de plantio irregular, ou seja, plantados pelos próprios moradores. "Não raro, observam-se palmeiras imperiais dividindo espaço com mangueiras ou árvores de outras espécies frutíferas em canteiros de vias importantes, plantadas por pessoas que habitam na redondeza." (RECCO, 2005, p.108).

Em um estudo realizado pela Prefeitura Municipal de Porto Alegre nove por cento das espécies de árvores encontradas nas ruas são frutíferas alimentares. Uma situação pouco freqüente na cidade formal, mas de uso corriqueiro nos bairros populares. Destas, quatro espécies correspondem a $55 \%$ do total plantado: abacateiro, pitangueira, bananeira e goiabeira (MASCARÓ e MASCARÓ, 2003).

Em outro estudo realizado nas ruas do bairro de Copacabana no Rio de Janeiro também se encontrou um número significativo de árvores úteis à alimentação humana: $6 \%$, e principalmente mangueiras e abacateiros.

Jaqueiras, mangueiras, goiabeiras, abacateiros, pitangueiras, amoreiras, jamelões, entre outras, espalham-se silenciosamente pelas calçadas de Copacabana, nos revelando talvez um desejo oculto de cultivo de um verdadeiro pomar urbano. Árvores frutíferas que outrora vicejavam nos antigos quintais das residências do bairro, hoje são plantadas pelos moradores locais, principalmente porteiros e pequenos comerciantes que, por força da profissão, tem o contato cotidiano com a calçada (COSTA et al, 1996, p.81).

Como se observou, alguns autores são contra esse tipo de arborização, porém existem outros que apóiam e incentivam a iniciativa de produzir alimentos em áreas públicas. Também foi salientada a importância das frutas na saúde humana e que existem alguns exemplos bem sucedidos de árvores produzindo alimentos nas ruas de algumas cidades do Brasil e do mundo, onde a população convive com essas árvores aproveitando os seus benefícios.

Outro benefício que merece destaque é o que se relaciona coma a avifauna. Segundo Almeida et al (2008) a principal fonte de alimentação para a fauna urbana está na vegetação. É através dela que mamíferos, aves, répteis e anfíbios adquirem os frutos, as flores, o néctar e os insetos. Neste contexto, as árvores frutíferas plantadas ou cultivadas nas cidades são de grande valia para manter o equilíbrio e a harmonia do ecossistema urbano. 


\section{MATERIAIS E METODOS}

O presente inventário foi realizado no bairro de Santa Felicidade, que está localizado na parte noroeste do município de Curitiba, tratando-se de um bairro predominantemente residencial, mas com um forte centro comercial, sendo considerado o maior centro gastronômico da cidade.

Dada a grande extensão do bairro $\left(12,27 \mathrm{~km}^{2}\right)$, a área pesquisada limitou-se à sua porção central, o que equivale a aproximadamente $35 \%$ da área total do bairro (FIGURA 01). A escolha da porção central deve-se ao fato de nela estar localizada um movimentado centro gastronômico, ponto turístico de Curitiba, e seu entorno ser ocupado por residências. Desta forma, a paisagem é heterogênea, sendo possível comparar uma área onde o planejamento urbano é mais presente, pelo fato de se tratar de um ponto turístico, e outra área em que a realização de projetos de arborização de calçadas pode não ser tão intensa.

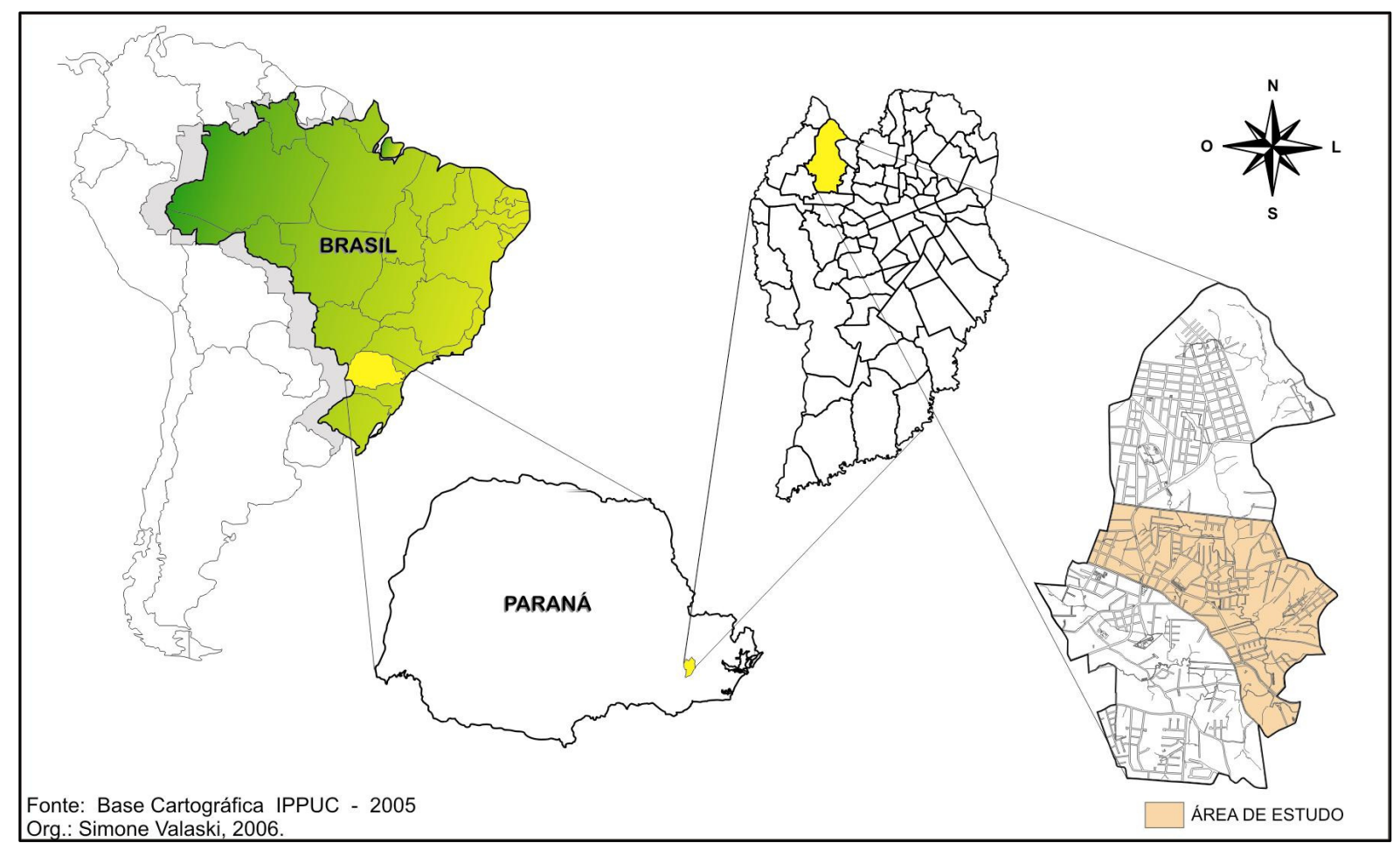

Figura 01 - localização da área de estudo

Na identificação das espécies foi aplicada a metodologia proposta por Roderjan e Barddal (1998), na qual é apresentado um quadro sinóptico informando aspectos fenológicos (época e cor das flores, época e tipo dos frutos e quedas das folhas), porte da árvore, forma da copa, aparência da casca externa e características das folhas (tipo, forma, margem, inervação e pilosidade). A bibliografia complementar utilizada como referência na identificação das árvores, foram os manuais de Lorenzi (1992, 2002 e 2003) e Biondi e 
Althaus (2005), todos ricos em fotografias e descrição das características principais das plantas.

Utilizou-se como critério inventariar os indivíduos de porte arbóreo acima de $2 \mathrm{~m}$ de altura e que estivessem localizados próximos à via pública. O inventário foi realizado entre os meses de maio e outubro de 2006, perfazendo um total de 39 horas de trabalho de campo.

Algumas calçadas, ainda não urbanizadas, encontravam-se ocupadas com espécies de diferentes fases de sucessão da vegetação original da região, ou seja, da Floresta Ombrófila Mista (Mata com Araucárias), o que também não permitiu a identificação desses indivíduos com base na chave proposta por Roderjan e Bardall (1998).

\section{RESULTADOS E DISCUSSÃO}

Foram encontradas 1806 árvores nas calçadas da área estudada, sendo que 1094 não são consideradas frutíferas, ou seja, não produzem frutos comestíveis pelo ser humano, 433 não puderam ser identificadas até o presente momento e 279 são consideradas frutíferas, pois produzem alimentos consumíveis pelos seres humanos. (Tabela 01)

Tabela 01 - Espécies arbóreas nas calçadas do bairro de Santa Felicidade (Curitiba/PR).

\begin{tabular}{llccc}
\hline \multicolumn{1}{c}{ Nome popular } & \multicolumn{1}{c|}{ Nome científico } & Quant. & Porcentagem \\
\hline Tipuana & Tipuana tipu & 402 & 22,26 \\
Alfeneiro & Ligustrum lucidum & 209 & 11,57 \\
Jerivá & Syagrus romanzoffiana & 62 & 3,43 \\
Dedaleiro & Lafoensia pacari & 58 & 3,21 \\
Cipreste & Cupressus sp. & 54 & 2,99 \\
Pinheiro & Araucaria angustifolia & 51 & 2,82 \\
Pitangueira & Eugenia uniflora & 47 & 2,60 \\
Ipê & Tabebuia sp & 44 & 2,44 \\
Aroeira & Schinus terebinthifolia & 42 & 2,33 \\
Pinheiro bravo & Podocarpus lambertii & 41 & 2,27 \\
Ficus & Ficus sp. & 30 & 1,66 \\
Extremosa & Lagerstroemia indica & 27 & 1,50 \\
Cinamomo & Melia azedarach & 25 & 1,38 \\
Quaresmeira & Tibouchina sellowiana & 24 & 1,33
\end{tabular}




\begin{tabular}{llcc} 
Amoreira & Morus nigra & 19 & 1,05 \\
Ameixeira & Prunus domestica & 18 & 1,00 \\
Araçá & Psidium cattleianum & 18 & 1,00 \\
Cipreste dourado & Chamaecyparis obtusa & 17 & 0,94 \\
Canafístula-A & Cassia leptophylla & 12 & 0,66 \\
Espirradeira & Nerium oleander & 11 & 0,61 \\
Cassia manduirana & Senna macranthera & 11 & 0,61 \\
Abacateiro & Persea americana & 10 & 0,55 \\
Mamoeiro & Carica sp. & 10 & 0,55 \\
Pinus & Pinus sp. & 10 & 0,55 \\
Bracatinga & Mimosa scabrella & 8 & 0,44 \\
Goiabeira & Psidium guajava & 8 & 0,44 \\
Àcer & Acer negundo & 6 & 0,33 \\
Laranjeira & Citrus sp. & 6 & 0,33 \\
Hibisco & Hibiscus rosa sinensis & 5 & 0,28 \\
Pinheiro-alemão & Cunninghamia lanceolata & 5 & 0,28 \\
Guabirobeira & Campomanesia xanthocarpa & 5 & 0,28 \\
Mexeriqueira & Citrus sp. & 5 & 0,28 \\
Outras & & 59 & 3,27 \\
Total & Não Identificadas & 433 & 23,98 \\
\hline FONTE: & & 1806 & 100,00 \\
\hline
\end{tabular}

FONTE: Carvalho et al. (2007).

Os 279 indivíduos com potencial para uso na alimentação humana correspondem a $15,4 \%$ do total, (FIGURA 02).

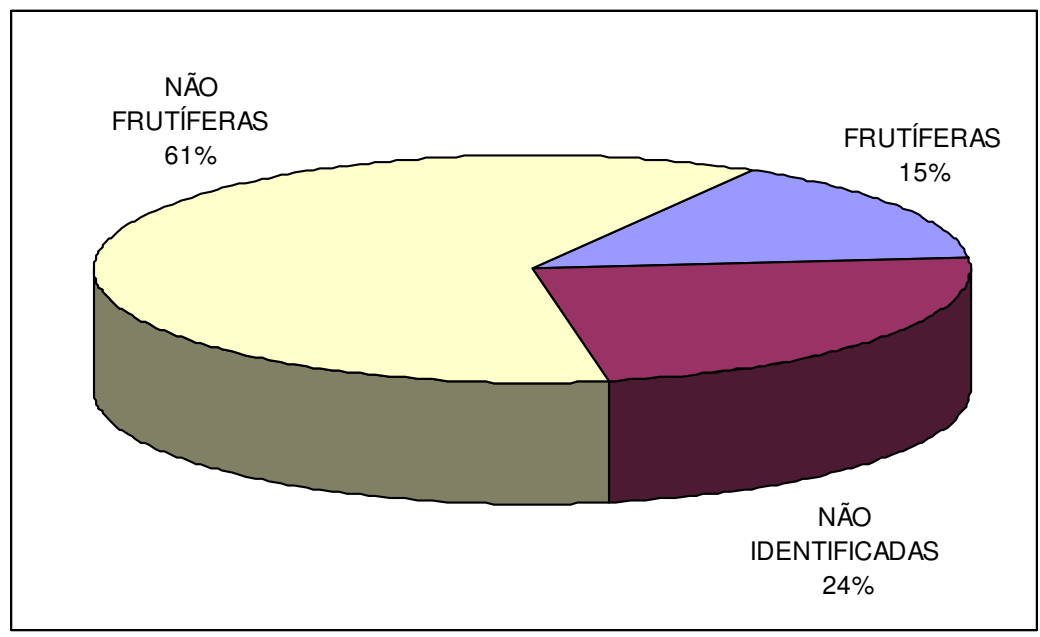


Figura 02 - proporção entre árvores produtoras e não produtoras de alimentos comestíveis pelos seres humanos, em relação à quantidade total

Observou-se que o bairro é bastante arborizado, com muitas árvores tanto nos quintais, quanto nas calçadas, nos canteiros centrais de avenidas e nas praças, sendo que na parte comercial existe uma arborização mais planejada que nas áreas periféricas. Nas áreas comerciais as espécies mais encontradas são Tipuana tipu (tipuana) com 22,26\% e Ligustrum lucidum (alfeneiro) com $11,57 \%$ do total. Nestas áreas caracterizadas pela homogeneização das espécies de árvores o poder público realizou a arborização demonstrando uma preocupação principalmente estética.

As áreas mais afastadas, principalmente as residenciais, são caracterizadas por uma arborização irregular (realizada principalmente pelos moradores ou de nascimento espontâneo). Percebe-se isso pela falta de alinhamento entre as árvores e a grande variedade de espécies intercaladas, formando uma paisagem diferente da que se observa nas avenidas principais.

As espécies de árvores frutíferas encontradas estão relacionadas na tabela 02 e a distribuição destas espécies no bairro estão representadas na figura 02.

Tabela 02 - espécies úteis à alimentação humana encontradas em Santa Felicidade Curitiba/PR

\begin{tabular}{llccc}
\hline \multicolumn{1}{c|}{ Nome comum } & \multicolumn{1}{c|}{ Nome científico } & Quantidade & \% Relativa \\
\hline Jerivá & Syagrus romanzoffiana & 62 & 22,2 \\
Pinheiro & Araucaria angustifolia & 51 & 18,3 \\
Pitangueira & Eugenia uniflora & 47 & 16,8 \\
Amoreira & Morus nigra & 19 & 6,8 \\
Ameixeira & Prunus domestica & 18 & 6,5 \\
Araçazeiro & Psidium cattleianum & 17 & 6,1 \\
Limoeiro & Citrus limão & 13 & 4,7 \\
Abacateiro & Persea americana & 10 & 3,6 \\
Mamoeiro & Carica sp. & 10 & 3,6 \\
Laranjeira & Citrus simensis & 6 & 2,2 \\
Goiabeira & Psidium guajava & 5 & 1,8 \\
Guabirobeira & Campomanesia xanthocarpa & 5 & 1,8 \\
Mexeriqueira & Citrus sp. & 5 & 1,8
\end{tabular}




$\begin{array}{llcc}\text { Cerejeira } & \text { Eugenia involucrata } & 3 & 1,1 \\ \text { Butiazeiro } & \text { Butia capitata } & 2 & 0,7 \\ \text { Caquizeiro } & \text { Diosyros sp. } & 2 & 0,7 \\ \text { Pessegueiro } & \text { Prumus persica } & 2 & 0,7 \\ \text { Macieira } & \text { Malus sp. } & 1 & 0,4 \\ \text { Romazeira } & \text { Punica granatum } & 1 & 0,4 \\ \text { Total } & & 279 & 22,2\end{array}$

FONTE: Carvalho et al. (2007).

O jerivá, o pinheiro (araucária) e a pitangueira são as espécies predominantes, somando juntas mais que $50 \%$ do total, sendo nativas da região.

Nas áreas mais periféricas do bairro, onde o planejamento efetuado pelo poder público ainda não se faz muito presente, foi encontrado um número considerável de espécies que são úteis à alimentação humana, inclusive há moradores que plantam mais de uma árvore produtora de frutas em frente às suas casas, formando pequenos pomares.

Em uma residência, de classe um pouco mais baixa, foram encontradas quatro pitangueiras formando uma espécie de corredor nos lados da calçada de entrada da residência.

Também se observou que muitos moradores, por iniciativa própria, plantam árvores frutíferas em vários locais, algumas vezes sem seguir as normas técnicas e deixando o local com aspecto pouco estético, com várias árvores juntas e muito próximas ao muro. Talvez exista uma boa vontade por parte dos moradores, mas falta uma correta orientação.

Não se pode esquecer das praças, onde também foram encontradas árvores frutíferas nas calçadas, tais como ameixeiras e jerivás, evidenciando uma iniciativa interessante do poder público ao plantar esse tipo de árvore nesses locais.

É importante ressaltar que o bairro tem uma riquíssima avifauna. Uma moradora que mantém várias árvores frutíferas dentro e fora de seu quintal relatou que já observou, além de vários pássaros, serelepes e até um sagüi se alimentando dos frutos das árvores. 


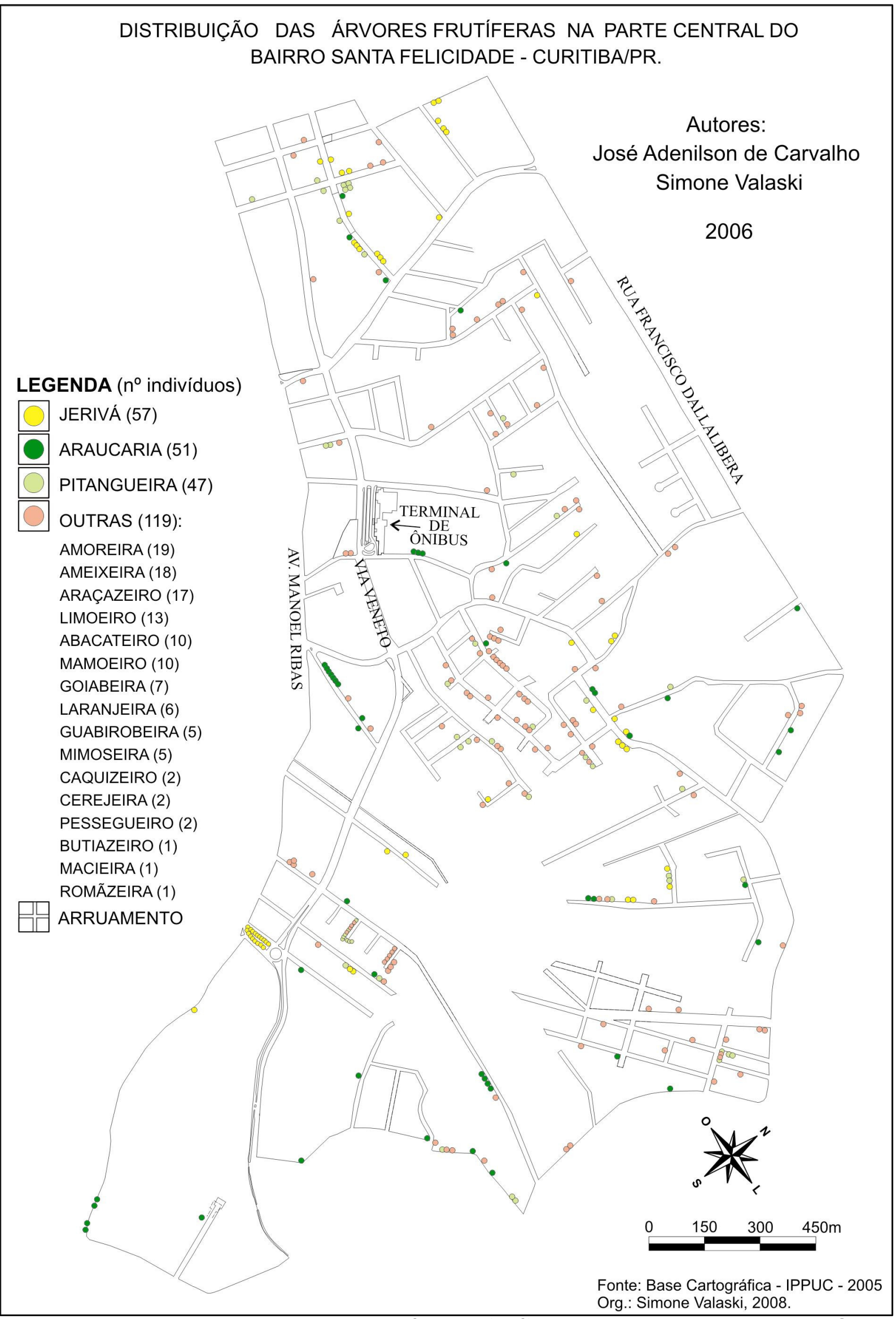

Figura 03 - mapa com a localização das árvores frutíferas na parte central do bairro Santo 
Felicidade - Curitiba/PR

\section{CONCLUSÕES}

Observou-se que uma parcela significativa da população do bairro tem preferência por árvores frutíferas, mesmo em calçadas, e mantém seu cultivo, principalmente nas áreas onde o poder público não desenvolve uma arborização planejada.

Foi constatado que a proporção de espécies frutíferas, fornecedoras de alimento para os seres humanos, é relativamente elevada, gerando alguns benefícios para a comunidade local, tais como, a possibilidade de colher frutos nas próprias calçadas, além de potencializar a atração de pequenos animais, principalmente pássaros.

Além das inúmeras qualidades que as árvores plantadas nas calçadas possuem e os benefícios que elas proporcionam, o plantio das frutíferas ajuda a formar um ambiente mais equilibrado, propiciando bem-estar e alimentos de graça para a população, bem como sustentando a avifauna urbana, aproximando a natureza e a moderna sociedade urbanizada.

\section{REFERÊNCIAS}

ALMEIDA, A.R. de; ZEM, L. M.; BIONDI, D. Relação observada pelos moradores da cidade de Curitiba-PR entre a fauna e árvores frutíferas. Disponível em: http://www.revsbau.esalq.usp.br/artigos_cientificos/artigo70-versao_publicacao.pdf. Acesso em 24-11-2009.

BEZERRA, M. C. L.; FERNANDES, R. C. Redução das desigualdades sociais. Brasília: Ministério do Meio Ambiente e dos Recursos Renováveis, Consórcio Parceria 21, 2000. $180 \mathrm{p}$.

BIONDI, D; ALTHAUS, M. Árvores de rua de Curitiba - cultivo e manejo. Curitiba: FUPEF, 2005.

COSTA, L. M. S. A. et al. Arborização das ruas do bairro de Copacabana. In: III CONGRESSO BRASILEIRO DE ARBORIZAÇÃO URBANA, 11, 1996, Salvador. Anais..., 1996. p.79-88. 
FERREIRA, L. A. B. Usos da vegetação In: ENCONTRO NACIONAL SOBRE ARBORIZAÇÃO URBANA, 10, 1985, Porto Alegre. Anais... Porto Alegre: Prefeitura Municipal de Porto Alegre - Secretaria Municipal do Meio Ambiente, 1985. p. 89-95

MANICA, I. Fruticultura em áreas urbanas. Porto Alegre: Cinco Continentes Editora. 1997. $154 \mathrm{p}$.

LORENZI, H. Árvores Brasileiras: manual de identificação e cultivo de plantas arbóreas nativas do Brasil. Nova Odessa: Instituto Plantarum, 1992, 368p.

LORENZI, H. Árvores Brasileiras: manual de identificação e cultivo de plantas arbóreas nativas do Brasil. Vol. 2. 2ª ed. Nova Odessa: Instituto Plantarum, 2002, 384p.

LORENZI, H. Árvores Exóticas no Brasil: madeireiras, ornamentais e aromáticas. $2^{\mathrm{a}}$ ed. Nova Odessa: Instituto Plantarum, 2003. 384p.

MASCARÓ, L. E. A. R. de; MASCARÓ, J. L. Vegetação urbana. Porto Alegre: L. Mascaro, 2003. 210p.

MASCARÓ, J. L. Loteamentos urbanos. Porto Alegre: L. Mascaro, 2002. 242p.

MELLO FILHO, L. E. Arborização Urbana. In: ENCONTRO NACIONAL SOBRE ARBORIZAÇÃO URBANA, 10, 1985, Porto Alegre. Anais... Porto Alegre: Prefeitura Municipal de Porto Alegre: Secretaria Municipal do Meio Ambiente, 1985. p.117-127.

MILANO, M. S. Arborização Urbana no Brasil: Mitos e Realidade. In: III CONGRESSO BRASILEIRO DE ARBORIZAÇÃO URBANA, 11, 1996, Salvador. Anais..., 1996. p.1-6.

MILANO, M. S. ; DALCIN, E. Arborização de Vias Públicas. Rio de Janeiro: 1. Ed. 2000. 226p.

$\mathrm{NUCCl}$, J. C. Qualidade ambiental e adensamento urbano: um estudo de ecologia e planejamento da paisagem aplicado ao distrito de Santa Cecília (MSP). São Paulo: Humanitas/FFLCH/USP, 2001. 236p. 
PENTEADO, A. R. Belém - Estudo de Geografia Urbana. 183f. Rio de Janeiro,1968. Tese (Livre-docência na cadeira de Geografia do Brasil) - Faculdade de Filosofia, Ciências e Letras, Universidade de São Paulo.

PINHO, A. J. V.; CAETANO, V. R.; RODRIGUES, L. A. S. Arborização urbana com segurança, paisagismo e produção de alimentos. In: I ENCONTRO GAÚCHO DE ARBORIZAÇÃO URBANA, 11, 1999, Pelotas. Anais eletrônicos ... Disponível em: <http://www.sbau.com.br/arquivos/gaucho_arborizacao/Anais_do_evento/POSTER8/poster8 .HTM>. Acesso em 06/10/2004.

RECCO, R. À sombra dos ipês da minha terra. Londrina, PR:Midiograf, 2005. 112p.

RODERJAN, C.V.; BARDALL, M.L. Arborização das ruas de Curitiba-Paraná: guia prático para identificação das espécies. Curitiba: FUPEF, 1998. 14p.

SANCHOTENE, M. C. C. Fruteiras nativas úteis à fauna na arborização urbana. In: ENCONTRO NACIONAL SOBRE ARBORIZAÇÃO URBANA, 10, 1985, Porto Alegre. Anais... Porto Alegre: Prefeitura Municipal de Porto Alegre: Secretaria Municipal do Meio Ambiente, 1985. p. 105-111.

SANTOS, N. R. Z.; MÓR, J.V. Relação espaço urbano, forma do vegetal e manejo. In: I ENCONTRO GAÚCHO DE ARBORIZAÇÃO URBANA, 11, 1999, Pelotas Alegre. Anais eletrônicos ... Disponível em: <http://www.sbau.com.br/arquivos/gaucho_arborizacao/ Anais_do_evento/poster1/poster1.HTM>. Acesso em 06/10/2004.

SANTOS, N. R. Z. dos; TEIXEIRA, I. F. Arborização de vias públicas: ambiente $\mathbf{x}$ vegetação. Santa Cruz do Sul: Instituto Souza Cruz, 2001. 135p.

SCHUMACHER, E. F. O negócio é ser pequeno. Um estudo de economia que leva em conta as pessoas. São Paulo: Círculo do Livro, 1973.

SOARES, M. P. Verdes urbanos e rurais: Orientação para a arborização de cidades e sítios campesinos. Porto Alegre: Cinco Continentes.1998. 242p.

TOMASINI, S. L. V.; SATTLER, M. A. Arborização urbana e sustentabilidade: uma proposta para o Centro Experimental de Tecnologias Habitacionais Sustentáveis (CETHS). In: IX 
ENCONTRO NACIONAL DE ARBORIZAÇÃO URBANA, 10, 2001, Brasília. Anais... Disponível em: <http://www.sbau.com.br/>. Acesso em: 06/10/2004.

TOLEDO FILHO, D.V.; PARENTE, P.R. Aspectos da arborização urbana de uma cidade do interior. In: ENCONTRO NACIONAL SOBRE ARBORIZAÇÃO URBANA, 10, 1985, Porto Alegre. Anais... Porto Alegre: Prefeitura Municipal de Porto Alegre - Secretaria Municipal do Meio Ambiente, 1985. p.155-162. 